\title{
The Independent Media of New Zealand FREE
}

Linda Jean Kenix, College of Arts, University of Canterbury

https://doi.org/10.1093/acrefore/9780190228613.013.963

Published online: 28 June 2021

\section{Summary}

New Zealand has high global measures for press freedom, democracy, and wealth. Historically, if a country has had strong index rankings for press freedom, democracy, and wealth, they also have a robust independent media system. However, that has not been the case in New Zealand where the independent media is lacking, despite the fact the country ranks extremely highly for press freedom, democracy, and wealth. The lack of a robust independent media in New Zealand may be due to five unique reasons: the small size of the country, the reliance on international news, a wariness toward the entire media landscape, the reserved culture of New Zealand, and the flood of content online.

Keywords: press freedom, democracy, wealth, independent media, local population, local culture, New Zealand, South Pacific

Subjects: International/Global Communication, Mass Communication, Media and Communication Policy

\section{Introduction}

It has been suggested that if a country has a high degree of press freedom, a fully functioning democracy, and a high degree of wealth then that country would have a robust independent media. However, New Zealand appears to negate this idea as there is a limited independent media but the country ranks very high on all of these indexes. So, does the size of New Zealand matter in determining a robust independent media system? Is there something unique about New Zealand that suggests fewer independent media titles? The example of New Zealand has global implications. This article first details what exactly independent media are in the mediated landscape. Then it explores the historical role of press freedom, democracy, and wealth in creating a robust independent media sphere. Finally, this article will ask important questions about New Zealand that should challenge the academic community which examines independent media. 


\section{Independent Media}

If communication is "the creative making of a social order" (Hamilton, 2000, p. 361), then the importance of independent media is clear. Social relations are created, confirmed, and recodified within communication processes. Relationships are formed and societal boundaries are laid through communication. Mutual understandings begin through effective communication and that happens, in large part, online. Such interconnected development is absolutely central to a thriving social network. Thus, the importance of media and communication in general, and independent media specifically, to such a society cannot be understated (Carey, 1989). Independent media are essential to communication across groups (Sparks, 1993).

Although undeniably important, defining independent media has historically been a problematic exercise for academics. Previously, academics used the term "alternative" to describe any media that was mainstream. However, that has become increasingly problematic with the explosion of online news sources in the 2000s and 2010s that were readily available for free viewing. Downing (2001) argued that the term alternative media is actually "oxymoronic" (p. ix) because everything is an alternative to something else. It has been said that the term "alternative" places too much legitimacy on the mainstream media by denoting somewhat of a secondary stature to a far more central-and therefore more importantmainstream press (Braden, 2007). Hence, much scholarship now prefers labels such as "independent" media (Downing, 2001), although researchers and practitioners have also called for alternative media to be labeled as "activist" or "citizens" media, or possibly "tactical" or "autonomous" media, or "radical" media. Related terms are "participatory" or "community" media. Each of these conceptualizations attempts to capture what is unique about media that exists outside of corporate entities. However, the term "independent media" encapsulates all of these labels as a descriptor of the autonomous ownership model as well as the sovereign and self-ruling content. All alternative media are independent, but, it must be said that, not all independent media need be alternative-although capitalistic forces eventually dictate this distinction as well. If independent media outlets told stories within the same frame as mainstream media, and not an alternative frame, then consumers would not perceive enough of a difference to devote attention to those independent voices when mainstream outlets are so pervasive. Although the term independent media is used predominantly in this article, much of the research that is drawn upon is historical and thus examines this field using the terms alternative as well as independent. ${ }^{1}$ Therefore, this article will use these terms interchangeably when they come from secondary research, but will use the term independent in all primary content. The purposeful intent is to move away from "alternative" as a descriptor of what is independent media.

There are many other distinctions between independent mainstream media. Independent media invite participation in the creation of content and engage in reciprocal communication outside of strictly commercial exchanges found in mainstream outlets. Independent media are often free of the bureaucratic processes or commercial responsibilities that constrain mainstream media. Furthermore, independent media are independent of other social institutions (Albert, 2006). 
An often cited definition of alternative media suggests that it "challenges, at least implicitly, actual concentrations of media power" (Curran \& Couldry, 2003, p. 7). Couldry (2003) argues that these challenges are intrinsic to the purpose of alternative media and are intrinsic to independent media as well. One definition of independent media puts that point of exclusion at the center of its defined meaning: independent media are best conceptualized as simply the media "produced by the socially, culturally and politically excluded" (Dowmunt \& Coyer, 2007, p. 5). This exclusion is also at the heart of Forde's definition of alternative media, which argues that

alternative journalism is political. It is not always radical; it is not always "progressive"; it is not always empowering; but it is always political because it is always a reminder of what the dominant forces in society are not providing, or are not able to provide.

(Forde, 2011, p. 45; original emphasis)

Atton (2004), a leading scholar in the field of alternative and independent media research, offers the following definition of alternative media: it is a "range of media projects, interventions and networks that work against, or seek to develop different forms of, the dominant, expected (and broadly accepted) ways of 'doing' media" (p. ix). This is a farreaching definition that allows for an expansive assortment of expression. In another article, Atton (2002) argues that alternative media should be fundamentally grounded in the cultural forms of an independent media outlet and also possess some, if not all, of the following attributes: rely upon modern, evolving technology; deprofessionalized organizational norms and roles; horizontal communication patterns; cultural or political radical content; compelling aesthetic form; innovative and independent distribution practices. In keeping with a more open and fluid definitional framework, Dowmunt and Coyer (2007) write that alternative media should be defined as "more accessible and participatory, and less constrained by bureaucracy or commercial interests than the mainstream media and often in some way in explicit opposition to them" (p. 1). Such a loose framework allows for a wide and comprehensive range of analysis.

Although independent media are autonomous from mainstream media, much research puts them in direct opposition to one another. It is essential, however, that the division between independent and mainstream media is not conceptualized as a mutually exclusive binary. Certainly, media outlets can possess some of the attributes outlined by Atton (2004), and also have attributes that better define them as mainstream. However, it is important that these definitions are not fixed, and that scholars are cognizant of the inherent subjective flexibilities within modern culture. What defines a media as independent within a particular moment of culture and time, might be labeled mainstream within a different cultural time and place (Dowmunt \& Coyer, 2007).

Independent media thrive when born out of very individualistic, unique political and cultural events and issues. Many independent media can be short-lived given a lack of advertising support, but, when called upon, independent media serve an interdependent function with social movements in pushing social change. They do not exist in a vacuum. They are always "media plus organisation" (Stoney, 2005). This places independent media within a very specific space and time within culture. They exist within that context to the degree that each 
definition of independent media, and indeed each example of independent media, is also a unique theory of political change (Dowmunt \& Coyer, 2007). Independent media are intrinsically part of the process of social change (Albert, 2006). As part of that process, independent media tend to exist within two organizational frameworks: participatory or hierarchical. Mainstream media operate almost exclusively within the latter category, but independent media have also co-opted this professionalized format as well. When an organization operates under a passive model of instruction, the "agents of resistance," or the actual receivers of the media message, can be artificially distanced from those who are "directing them" (Atton, 2002, p. 103). This prescriptive method of independent media communication is evident within modern forms of independent media and can best be explained by the mass culture approach to independent communication. Through professionalized norms and processes, such media is far more likely to "reach" a more substantial number of people and, therefore, be more effective. However, readers can also feel rather discouraged and disconnected from those who dictate behavior from an elite and hierarchical position.

Elite movement intellectuals from independent media can also help to "articulate the knowledge interests and cognitive identity of social movements" (Eyerman \& Jamison, 1995, p. 450). They serve as an ideological "point person" for members to connect with on a personal level. When such a person emerges from within the social movement itself, then they become more of a "facilitator, interpreter, and synthesiser, rather than ideological leader" (Eyerman \& Jamison, 1991, p. 116). This is often how independent media begin and how they then thrive.

There can also be a lateral form of organization and communication that includes "multiple experiences and concerns" (Downing, 1984, p. 19) that is in direct opposition to the mass culture approach. This model of independent media aims to create an alternate "value system" (Rau, 1994, p. 13) from a community of engaged participants. Eyerman and Jamison (1991) call this process of identity creation within a unified membership, knowledge production. More voices within independent media implicitly democratize the content. This removes the "hierarchy of access" (Glasgow University Media Group, 1976) that is endemic to mainstream media reporting processes. Independent media that welcome a diverse range of input are "transformed into an egalitarian, devolved communicational tool for theory and for action" (Atton, 2002, p. 111). This is one of the central arguments toward including readers/ writers as contributors to independent media. Otherwise, the creators of content that might be intended as emancipatory in nature, might actually be acting much more like colonists. This moves the message creator away from the center of an engaged, active debate and informed discussion toward a colonizing perspective whereby the creator is "placed either above or at the centre of things, yet apart from them" (Spurr, 1993, p. 16). Native reporters can actually document their own reality and become empowered by the process. This firsthand information also elevates the knowledge and discussion within the larger community as it is more relevant and far more informed than an elitist perspective from outside the close network of community relationships. This process further pulls "power away from the mainstream back to the disenfranchised and marginalized groups that are the native reporter's proper community" (Atton, 2002, p. 115). Native reporting validates the identity of communities that are increasingly overlooked in conglomerate, mainstream news. Yet 
confusion and disorganization can also be potential negative influences of native reporting and egalitarian forms of organization. Ideological focus can quickly be lost when there are a multitude of inputs all sharing attention (McKay, 1998).

As this review illustrates, simply defining independent media are has been a struggle in media scholarship. Perhaps understandably, very few theorists have contemplated how independent media, and in particular independent news media, might function in the future. In a 2011 article, titled, "The Future of Alternative Media?" (Kenix, 2011, p. 188), it was predicted that independent media would:

- Need to rely on cohesive portals of information and visual material for future success.

- Be increasingly politically subversive with very few differences between consumers and producers.

- Place a greater emphasis on local news and integrate social networking into every story.

- Rely upon unique, small-scale funding opportunities.

- See a further flattening of responsibilities but there will also be reduced thresholds for success.

- Nine years later, these predictions have proven correct on a global scale. However, New Zealand remains largely reliant on mainstream producers for content and has not seen a growth or even a stable independent press. The following section "Press Freedom, Democracy, and Wealth," examines the three most essential drivers of a country's independent press.

\section{Press Freedom, Democracy, and Wealth}

Independent media can only publish outside of mainstream outlets if there is a high degree of press freedom. Groups publish independent media "not because of a dedication to journalism, but as a means to reach people with ideas, to organise their movement and promote their beliefs" (Forde, 2011, p. 52). If there is no possible means to reach individuals through the media, then obviously groups simply do not attempt mediated publication through mainstream or alternative channels. A press system that is more open is associated with citizens that are more politically knowledgeable (Leeson, 2008). A more open press system results in individuals with better access to different forms of knowledge available across the media spectrum.

New Zealand has been ranked highly on press freedom indexes since at least 2000. Since 2002, Reporters Without Borders (2020) has placed New Zealand in the top 10 out of 180 countries in the world rankings for the majority of these years (Reporters Without Borders, 2021a). New Zealand was ranked seventh in 2019 for press freedom (Reporters Without Borders, 2020). All rankings are based upon the organization's own assessment of each country's press freedom records in the previous year. This ranking is comprised of responses to an online questionnaire that has seven sections: pluralism, media independence, media environment and self-censorship, legislative framework, transparency, infrastructure, and abuses (Reporters Without Borders, 2021b). The questionnaire is distributed to media professionals, lawyers, and sociologists who score each question on a scale from 0 to 100 . 
Reporters Without Borders ranks 180 countries according to the level of freedom from abuses and acts of violence against journalists for attempting to report the news (Reporters Without Borders, 2020).

Independent media, indeed all media, have historically become much more robust when there are possibilities for communication. If the less powerful and politically marginal can gain access to the media, then there are important consequences for the diversity of information available. If a society is more democratic, then it allows for those who have less power to speak in various forms of media, but particularly in what has been labeled alternative media (Cottle, 2008). As Hamilton and Atton (2008, p. 117) have said, "in modern democracies, there are expectations that the media will facilitate democracy by providing pluralistic information from which informed choices can be made and debates can take place."

A nation's level of democracy can be viewed from a formulation created by Campbell et al. (20 15). These authors have measured the quality of democracy by the degree of freedom (50\% of total measure) and performance of nonpolitical dimensions, each measured at 10\%: gender, economy, knowledge, health, and the environment. Out of 113 countries measured, Germany and Ireland have traded places with New Zealand in every year since 2010 for places seven, eight, and nine (Campbell et al., 2015). The Economist (2018) placed New Zealand as fourth out of 167 countries in 2018. By these measures, New Zealand has rated very high in terms of global measures of democracy since 2010.

A robust, independent media has long been tied to the level of wealth available in a country (Hackett et al., 2003). Media industries are now viewed as a business that must meet profitability measures, rather than as a public service. In that context, economics are paramount. A country that has more access to wealth inherently has more opportunities for all media to thrive.

New Zealand is a relatively wealthy country. The country has the 53rd largest economy in the world, out of 195 countries, when ranked by nominal gross domestic product (GDP) per capita. When one factors in housing, then the country is fifth in the world, according to the Global Wealth Report (Newshub, 2019). Visual Capitalist (Ghosh, 2019) places New Zealand at sixth in the world in terms of the a country's mean wealth per adult. Again, by these measures New Zealand is among the wealthiest countries in the world.

Thus, New Zealand ranks high on global measures for press freedom, democracy, and wealth. Historically, if a country has had strong index rankings for press freedom, democracy, and wealth, they also have a robust media system-and that includes an independent media sphere (Kenix, 2019). Thus, it would appear that the possibilities for a robust media sphere seemingly would increase with increased press freedom, democracy, and wealth. However, that has not been the case in New Zealand.

\section{Independent Media in New Zealand}

Before entering into this conceptual discussion about why New Zealand does not possess a robust independent media, a brief review about the pragmatics of independent media in New Zealand is warranted. It must be noted that there are examples of what can be conceptualized as alternative or independent media in New Zealand historically and online. There was a 
particular increase in alternative press activity during the late 1960s and early 1970s. There are several early examples from New Zealand independent publications that illustrate how marginalized groups aimed to fill informational gaps left by mainstream media. The early 20th-century New Zealand Protestant magazine The Nation argued against the pervasive proliferation of Catholic ideology throughout society, while the long-running women's newsletter Women's Electoral Lobby argued that "all the good works and achievements of those in the feminist movement are daily undermined by the images of women, children and Maori shown on television" (McLeod, 1988). These magazines and other independent publications attempted to create content decidedly opposite to mainstream media fare. During the 1960s and 1970s, Earwig was the only New Zealand member of the Underground Press Syndicate (UPS). This syndicate was a network of countercultural newspapers and magazines that began in the United States and extended around the globe (Kenix, 2010). The result was a rapid expansion of anarchist news stories and countercultural critique throughout these independent publications that would have otherwise remained dormant in relatively obscure magazines peppered around the globe. This practice ended in the 1970s and there has not been a syndicate to replace it. Earwig, The Nation, and The Women's Electoral Lobby, as well as countless other independent publications from that era, no longer exist.

In contemporary times, Scoop is a New Zealand publication that endeavors to circumvent any opinion from journalists by publishing public relations releases (see "Scoop's Mission_<http:// www.scoop.co.nz/about/mission.html>"). In doing so, the publication states its absolute independence. It is the fifth most popular blog in New Zealand (Feedspot, 2021a). However, an obvious limitation of pure public relation releases is that there is no independent analysis from a journalist. There are several other independent blogs in New Zealand, including The Spinoff. This Spinoff blog boasts 83,000 Facebook likes and 32,000 Twitter followers (Feedspot, 2021a) and had 240,000 weekly audience members in 2018 (The Spinoff, 2018). In a country of nearly 5 million people, this is reasonable penetration, but the outlet stands relatively alone, whereas other countries have a multitude of independent outlets. For example, the first ranked blog for popularity in New Zealand is a blog on the mainstream newspaper site, Stuff. Indeed, most of the top ranked blogs in New Zealand are mainstream news organizations or amalgamated sites, such as Reddit, for the keyword "New Zealand" or "New Zealand beer." After The Spinoff, the next truly independent blog is Happy Mum Happy Child, coming in at 10 th in terms of popularity.

It is important to note that there are independent blogs, which have a devoted, but stubbornly small, following in New Zealand. Sites such as Public Address, Werewolf, and E-Tangata all deserve a mention. There are other independent, alternative outlets as well. However, there is no robust, independent media platform in New Zealand. One has to actively search for sources online, and they are not easily located. These outlets are not well known in the mediated landscape of New Zealand. Mainstream media still dominates in New Zealandeven, paradoxically, as they are both growing and shrinking. Yes, the pervasiveness and visibility of mainstream media have exploded, "driven primarily by the needs and pressures exerted by an ever-expanding, globally triumphant capitalist economy" (Dowmunt \& Coyer, 2007, p. 4). Yet, while mainstream media have grown in visibility and potential reach, they have also reduced in number and in readership. The New Zealand Herald peaked in terms of circulation in 2006, with over 200,000 copies (Scoop, 2006). This date was several years agoeven though the population has continued to increase. 
Reductions in circulation are due to either consolidation within a larger, parent corporation or simply closure due to a lack of revenue. Such declines have meant a constant threat of redundancy within the mainstream media industry. The reduction of newsrooms across the globe are due to a lack of profits that are expected by the multinational, conglomerated corporations which now own much of the media in existence. News editors reporting back to disgruntled shareholders must find cost-cutting measures somewhere within the industry and that typically comes in the form of job losses. As Fuchs (2009) argues, "there is an economic interest in the substitution of living labour by technology to decrease the investment and reproduction costs of capital and its turnover time, which in the ideal case increases profit" (p. 382). The 21st-century media conglomeration is itself representative of an essential component of capitalism (Knoche, 2007).

Very few cities across the globe can boast more than one major daily newspaper-and certainly that is the case in New Zealand. There are four major centers: Dunedin, Christchurch, Wellington, and Auckland. Each city is served by only one major newspaper-a newspaper that is often part of an overseas conglomerate. The transnational companies, APN News and Media (ANM) and Fairfax, own 16 (72\%) of the 22 peripheral provincial newspapers (News Publishers Association, 2006). If provincial and metropolitan outlets are combined, independent mainstream newspapers account for only $8.6 \%$ of all newspapers in New Zealand (Lealand, 2008). Furthermore, the threat of replacing the relatively few remaining city newspapers with a larger regional paper remains omnipresent in media discussions. Thus, discussions surrounding the quality and the quantity of mainstream media are highly variable.

\section{Potential Reasons for a Relative Lack of Independent Media in New Zealand}

New Zealand negates the idea that increased press freedom, democracy, and wealth will result in a robust independent media. The potential reasons for this are many and complex. One possible reason that independent media are not as prolific in New Zealand is simply the size of the country. There are several possible reasons that size may be an influencing factor. As of 2021, the country of New Zealand is approaching 5 million people. The parliament of New Zealand consists of 121 members. In contrast, there are 100 senators in the United States, but there are 330 million people. This makes the ratio of representatives to the population 5:121 in New Zealand and 330:100 in the United States. Thus, the ratio of representatives to the population is very high in New Zealand, relatively speaking. It is indeed very possible that an individual may personally know their democratic representative in New Zealand-if not directly then indirectly. This level of personalization removes any political abstraction and also makes it possible for an individual to approach their representative directly if they have any issues or concerns. This removal of political abstraction and the possibility of an individual relationship may reduce the prospect of a robust independent media sphere. There is no need to write a counterpoint to political events to incite broader action when a person can approach their representative directly and potentially sort out differences. 
In addition, living in a small community means by definition that more individuals are familiar with other individuals or have the potential to soon meet them. It may be that because of that potential relationship, that individuals in smaller countries simply do not want to "stir the pot" on the chance that their connection with another individual may occur at some point in the future.

The second reason for the lack of independent media may be a reliance on international news in New Zealand. Because of the relatively small size of New Zealand, there is a penchant to look overseas. A quote, originally in reference to Canada, applies to New Zealand as well: Canadians (and New Zealanders) "live in a world of second-hand experience" (Hackett et al., 2003 , p. 257). New Zealanders look overseas for their news. Most media outlets in New Zealand are foreign owned (Myllylahti \& Baker, 2020) and look to large media conglomerates for content. An example of this is the partnership between the New Zealand Herald and the Washington Post. The Herald regularly hosts content of The Post on its website. Whereas mainstream media cover issues that may have some applicability to the lives of New Zealanders, independent media in countries around the world tend to cover issues that have applicability only to the host country. There are no examples that could be located of independent media from another country in New Zealand. The media that are imported in New Zealand have tended to be mainstream and not independent. New Zealand continues to import media because economically influential countries, such as the United States and more populous countries, such as China, continue to set the world news agenda. New Zealand simply follows the global news flow of information. New Zealand media has a relatively low degree of transnational power in terms of garnering international news attention and setting the international news agenda due to "population, trade, cultural proximity, and geographic closeness" (Guo \& Vargo, 2020, p. 433).

The third reason for a potential lack of independent media in New Zealand may be that the New Zealand public have grown wary of their media and do not attend to any media en masse -so the perceived need of independent media is not apparent. It is well publicized that trust of those in the media is at an all-time low. However, commercialization of the media has been associated with a decline in that trust (Ariely, 2015)—and the New Zealand mainstream media is almost completely commercialized. The New Zealand Herald is owned by New Zealand Media and Entertainment (NZME), which is part of the Australian Radio Network that operates 32 newspapers and a multitude of other digital and radio networks. The remainder of mainstream media in New Zealand is almost exclusively owned by the conglomerate Stuff, a subsidiary of Australia's commercial Nine Entertainment, which owns countless broadcast, digital, and radio networks. This commercial conglomerate operates nine daily newspapers throughout New Zealand, as well as two weekly newspapers. Audience trust in the news media, heavily informed by conglomerated commercialization, is a "highly consequential factor, shaping audience selection of and response to media, and potentially impacting citizens' perceptions of the political system at large" (Tsfati \& Ariely, 2013, p. 760). It may be that the New Zealand public simply does not attend to any media because of that lack of trust that has derived from exposure to a heavily commercialized media. The lack of media exposure among New Zealanders is apparent in circulation numbers.

The population of New Zealand was 4.80 million in 2019 (World Population Review, 2021) and the circulation for the New Zealand Herald, the national newspaper, was 104,266 (Kiwiblog, 2019). This is $2.17 \%$ of the population. Dallas, a random city in the United States, had 
1,345,000 people in 2019 (United States Census, 2019) and the Dallas Morning News had a circulation of 98,000 in 2019 (Silber, 2019). This is $7.28 \%$ of the population. Wolverhampton, a random city in the United Kingdom, had 259,530 people in 2019 (UK Population, 2019) and the Express \& Star had a circulation of 36,276 in 2019 (ABC, 2020). This is $13.9 \%$ of the population. These are just a few random comparisons, but this points to a lack of interest in mainstream media in New Zealand. The Spinoff, listed as the top independent "blog or website in 2020" (Feedspot, 2021b) had 83,500 Facebook fans and 34,200 Twitter followers in 2019. It is difficult to ascertain the level of popularity that this translates to, but given that New Zealand has a population of nearly 5 million, this seems to be a relatively small number.

Public understanding of the social world derives, in large part, from media exposure over time (Ryan et al., 1998). There is an intrinsic relationship between representations in the media and societies' general understanding of the social world. The media determine what is "relevant" (Hertog \& McLeod, 1995, p. 4). The general New Zealand public is not attending to the media and that lack of mediated exposure may be, at least partially, responsible for a relatively low level of general knowledge in New Zealand. A questionnaire completed in 2018 with 1,000 voting-age New Zealanders found that most New Zealanders were not aware of basic knowledge, such as the names of the seven continents or fundamental financial literacy, such as calculations of interest (NZ Initiative, 2019). New Zealand was also not listed as one of the 25 smartest countries in the world according to IQ in 2019 (Madden, 2019). Obviously, this alone does not point to a lack of media exposure and correlation most certainly does not equal causation, but taken as a whole these findings are worrying.

The fourth reason for a potential lack of independent media in New Zealand may simply be the culture of New Zealand. Most people do not talk about politics in public. A lack of divisiveness so far exists in New Zealand. New Zealand Immigration (2019) states that locals are "friendly but reserved" and this reservation may be a reason for both this lack of divisiveness and the lack of independent media. Modesty is a very big part of what it means to be a New Zealander. Many news articles congratulate individuals when they show modesty concerning their accomplishments. The government of New Zealand emphasizes equality over freedom (Levine, 2012) and this means an equality of opportunity. This trait runs through New Zealand culture and may be central to why independent media is not utilized. Individuals simply think that New Zealanders all have an access to mainstream media to tell their story because they have an equal opportunity to do so. Fairness, transparency, and honesty are institutive to New Zealand culture (Levine, 2012). The idea that a transparent, fair media would not attend to the needs of New Zealanders is simply anathema, so there is no reason to have a vibrant independent press when a mainstream press will deliver all the content that you need.

In addition, New Zealanders are acutely aware of their geographic isolation. It takes three hours by plane to get to Australia, its nearest neighbor at over 1,000 miles away. Due to this isolation, it is part of the culture of New Zealand to look abroad-for experiences and also for news content. It is very common for Kiwis (New Zealanders) to work or travel overseas for an elongated period of time-commonly known as an overseas experience, or an OE. As a member of the British Commonwealth, New Zealand often compares it's political and social advancement to the other 54 countries in the commonwealth. This cultural reflexivity to acknowledge, and even privilege, perspectives from abroad is endemic to Kiwi culture. This is 
magnified perhaps due to the isolation of the country. In terms of looking abroad for media content, it is possible that Kiwis simply do not promote internal independent media because of this cultural reflexivity to external perspectives.

The fifth and final reason for a potential lack of independent media in New Zealand may be that the Internet is flooded with content. It may be that the average New Zealander simply does not see the division between mainstream and independent media in a mediated system that is now flooded with content. There is, of course, the same conundrum around the world: How can an independent press stand out in a sea of online mediated content? However, New Zealand may be uniquely susceptible to this view of a flooded media landscape because of the previous four reasons for the lack of a robust independent media: the small size of the country, the reliance on international news, a wariness with regard to the entire media landscape, and the reserved culture of New Zealand. The most popular sites are YouTube, Facebook, Wikipedia, Twitter, Amazon, Google Play, and Instagram (Hardwick, 2021). These sites take up the bulk of worldwide online traffic and New Zealanders may also be attending to those sites for the same reasons. New Zealanders are simply doing what everybody else is doing.

\section{Conclusion}

New Zealand breaks from tradition in terms of a robust independent press. It has high global measures for press freedom, democracy, and wealth. Historically, if a country has had strong index rankings for press freedom, democracy, and wealth, they also have a robust independent media system. However, that has not been the case in New Zealand. It was hypothesized in this article that New Zealand may not embrace independent media due to five unique reasons. First is the small size of the country. In an environment in which a person may personally know their democratic representative, they can easily approach this representative directly, thereby bypassing the need for an independent press.

Second, is the reliance on international news, which is predominated by mainstream voices. Third, is a wariness with regard to the entire media landscape, and fourth is the reserved culture of New Zealand. A lack of divisiveness so far predominates in New Zealand and equality is emphasized over freedom. Individuals think that New Zealanders all have an access to mainstream media to tell their story because they have an equal opportunity to do so. Fifth, is the flood of content online. New Zealand may be uniquely susceptible to this flooded media landscape because of the previous four reasons for the lack of a robust independent media. New Zealanders are simply attending to the media that they know the rest of the world is interested in without any thought as to the importance of an independent press.

So, where does this leave media scholarship that adheres to the importance of press freedom, democracy, and wealth to a robust independent media system? Obviously, research needs to examine the possibilities for an independent media on a country-by-country basis.

Generalizations across nation-states do not encapsulate the nuances in each country that may exist. Each culture must be thoroughly examined through research and then through important cross-national comparative studies. Such research might possibly better illuminate the importance of freedom, democracy, and wealth to media systems. The globe is moving faster and further toward a monolithic international news source and important questions 
about how this process influences independent media need to be explored. Most research to date has explored the effect of corporatization on the mainstream press, but research exploring the effects of mainstream corporatization on independent media is just as valid.

\section{Further Reading}

Atkinson, J., \& Kenix, L. J. (Eds.). (2019). Alternative media meets mainstream politics: Activist nation rising. Rowman \& Littlefield.

Atton, C. (Ed.). (2015). The Routledge companion to alternative and community media. Routledge.

Dahlgren, P. (2013). The political web: Media, participation and alternative democracy. Palgrave Macmillan UK.

Downing, J. (2003). Audiences and readers of alternative media: The absent lure of the virtually unknown. Media, Culture \& Society, 25(5), 625-645.

Edy, J. A., \& Snidow, S. M. (2011). Making news necessary: How journalism resists alternative media's challenge $\leq$ https://doi.org/10.1111/j.1460-2466.2011.01584.x>. Journal of Communication, 61(5), 816-834.

Figenschou, T. U., \& Ihlebæk, K. A. (2019). Challenging journalistic authority_<https://doi.org/ 10.1080/1461670X.2018.1500868>. Journalism Studies, 20(9), 1221-1237.

Groshek, J., \& Han, Y. (2011). Negotiated hegemony and reconstructed boundaries in alternative media coverage of globalization. International Journal of Communication, 5(1), 1523-1544.

Hamilton, J. A. (2020). Critical celebrations of independent media centers 20 years on <https:// doi.org/10.1177/0163443720926048>. Media, Culture \& Society, 42(6), 1019-1023.

Harcup, T. (2013). Alternative journalism, alternative voices. Taylor \& Francis Group.

Harlow, S. (2019). Recognizing the importance of alternative media < https://doi.org/ $\underline{10.1080 / 1461670 X .2017 .1364139>}$. Journalism Studies, 20(1), 117-135.

Kenix, L. J. (2011). Alternative and mainstream media: The converging spectrum < $<t t p: / /$ www.bloomsbury.com/uk/alternative-and-mainstream-media-9781849665209/>. Bloomsbury Academic.

Rauch, J. (2015). Exploring the alternative-mainstream dialectic: What "alternative media” means to a hybrid audience. Communication, Culture and Critique, 8(1), 124-143.

Rodriguez, C., Ferron, B., \& Shamas, K. (2014). Four challenges in the field of alternative, radical and citizens' media research $\leq$ https://doi.org/10.1177/0163443714523877>. Media, Culture \& Society, 36(2), 150-166.

Sandoval, M., \& Fuchs, C. (2010). Towards a critical theory of alternative media_<https:// www.sciencedirect.com/science/article/abs/pii/S0736585309000410>. Telematics and Informatics, 2(2), 141-150. 


\section{References}

ABC. (2020. Express \& Star circulation analysis <https://www.abc.org.uk/product/10110>.

Albert, M. (2006). What makes alternative media alternative? Toward a Federation of Alternative Media Activists and Supporters-FAMAS.

Ariely, G. (2015). Does commercialized political coverage undermine political trust? Evidence across European countries <https://doi.org/10.1080/08838151.2015.1055000>. Journal of Broadcasting \& Electronic Media, 59(3), 438-455.

Atton, C. (2002). Alternative media. SAGE.

Atton, C. (2004). An alternative Internet. Edinburgh University Press.

Braden, S. (2007). Mgwirzano: A case study from Malawi. In K. Coyer, T. Dowmunt, \& A. Fountain (Eds.), The alternative media handbook (pp. 212-223). Routledge.

Campbell, D. F. J., Pölzlbauer, P., Barth, T. D., \& Pölzlbauer, G. (2015). Democracy ranking (edition 2014): The quality of democracy in the world. Democracy Ranking.

Carey, J. W. (1989). Communication as culture: Essays on media and society. Unwin Hyman.

Cottle, S. (2008). Reporting demonstrations: The changing media politics of dissent. Media, Culture \& Society, 30(6), 853-872.

Couldry, N. (2003). Media rituals: A critical approach. Routledge.

Curran, J., \& Couldry, N. (Eds.). (2003). Contesting media power: Alternative media in a networked world. Rowman \& Littlefield.

Dowmunt, T., \& Coyer, K. (2007). Introduction. In K. Coyer, T. Dowmunt, \& A. Fountain (Eds.), The alternative media handbook (pp. 1-12). Routledge.

Downing, J. (1984). Radical media: The political experience of alternative communication. South End Press.

Downing, J. (2001). Radical media: Rebellious communication and social movements. SAGE.

Eyerman, R., \& Jamison, A. (1991). Social movements: A cognitive approach. Polity Press.

Eyerman, R., \& Jamison, A. (1995). Social movements and cultural transformation: Popular music in the 1960s. Media, Culture \& Society, 17, 449-468.

Feedspot. (2021a. Top 100 New Zealand blogs \& websites in 2019_https://blog.feedspot.com/ new zealand blogs/>.

Feedspot. (2021b). Top100 New Zealand blogs and websites in 2020<https://blog.feedspot.com/ new zealand blogs/>.

Forde, S. (2011). Challenging the news: The journalism of alternative and community media. Palgrave Macmillan.

Page 13 of 16

Printed from Oxford Research Encyclopedias, Communication. Under the terms of the licence agreement, an individual user may print out a single article for personal use (for details see Privacy Policy and Legal Notice).

Subscriber: Hamilton City Libraries; date: 02 July 2021 
Fuchs, C. (2009). Some theoretical foundations of critical media studies: Reflections on Karl Marx and the media. International Journal of Communication, 3, 369-402.

Ghosh, I. (2019, August 16). Which countries have the most wealth per capita? <https:// www.visualcapitalist.com/countries-wealth-per-capita/> Visual Capitalist.

Glasgow University Media Group. (1976). Bad news. Routledge \& Kegan Paul.

Guo, L., \& Vargo, C. J. (2020). Predictors of international news flow: Exploring a networked global media system <https://doi.org/10.1080/08838151.2020.1796391>. Journal of

Broadcasting \& Electronic Media, 64(3), 418-437.

Hackett, R. A., Pinet, R., \& Ruggles, M. (2003). News for whom? Hegemony and monopoly versus democracy in Canadian media. In H. Holmes \& D. Taras (Eds.), Seeing ourselves: Media power and policy in Canada (pp. 257-272). Abe Books.

Hamilton, J. (2000). Alternative media: Conceptual difficulties, critical possibilities. Journal of Communication Inquiry, 24(4), 357-378.

Hamilton, J., \& Atton, C. (2008). Theorizing alternative journalism. In C. Atton \& J. Hamilton (Eds.), Alternative journalism (pp. 117-135). SAGE.

Hardwick, J. (2021). Top 100 most visited websites in the world (as of 2019) <https:// ahrefs.com/blog/most-visited-websites/>.

Hertog, J., \& McLeod, D. (1995). Anarchists wreak havoc in downtown Minneapolis: A multi-level study of media coverage of radical protest. Journalism Monographs, 151(June), 1-48.

Kenix, L. J. (2010). Resistance narratives in radical, alternative media: A historical examination of Earwig <https://doi.org/10.1080/02560054.2010.9653413>. Equid Novi, 31(1), 89-113.

Kenix, L. J. (2011). The future of alternative media? <http://www.scopus.com/inward/record.url? eid=2-s2.0-79958140597\& partnerID=MN8TOARS $>$ Observatorio, 5(1), 187-214.

Kenix, L. J. (2019). Exploring national culture through international media: The publication of a viral pro-LGBT image compared against a nation's wealth, level of religion, and democracy. Journal of Intercultural Communication, 49(March), 1404-1634.

Kiwiblog. (2019). Latest newspaper circulation_<https://www.kiwiblog.co.nz/2019/06/ latest_newspaper_circulation.html>.

Knoche, M. (2007). Medienkonzentration. In B. Thomass (Ed.), Mediensysteme im internationalen Vergleich (pp. 122-144). UVK.

Lealand, G. (2008). Media in New Zealand, July 2008.

Leeson, P. T. (2008). Media freedom, political knowledge, and participation < $<$ ttps:// www.jstor.org/stable/27648246>. Journal of Economic Perspectives, 22(2), 155-170.

Levine, S. (2012). Political values: The fair society_<https://teara.govt.nz/en/political-values/ page-4>. Te Ara: The Encyclopedia of New Zealand. 
Madden, D. (2019). Ranked: The 25 smartest countries in the world_<https://www.forbes.com/ sites/duncanmadden/2019/01/11/ranked-the-25-smartest-countries-in-the-world/ $\# 1104 a c 8 c 163 f>$. Forbes, January 11.

McKay, G. (Ed.). (1998). DIY culture: Party and protest in nineties Britain. Verso.

McLeod, P. (1988). National co-ordinator's letter. Women's Electoral Lobby, 93, May.

Myllylahti, M., \& Baker, S. (2020). New Zealand media ownership 2019<https://www.aut.ac.nz/ study/study-options/communication-studies/research/journalism,-media-and-democracyresearch-centre/projects/new-zealand-media-ownership-report>.

Newshub. (2019). New Zealand makes list of world's wealthiest countries.

News Publishers Association. (2006). Industry overview.

New Zealand Immigration. (2019). Customs and communication_<https:// www.newzealandnow.govt.nz/living-in-nz/settling-in/customs-communication $>$.

NZ Initiative. (2019). New survey finds serious gap in New Zealanders' general knowledge_<https://nzinitiative.org.nz/reports-and-media/media/media-release-new-zealandhas-a-general-knowledge-problem $/>$.

Rau, M. (1994). Towards a history of fanzine publishing: From APA to Zines. Alternative Press Review, Spring/Summer, 10-13.

Reporters Without Borders. (2020). Reporters Without Borders <https://rsf.org/en/ranking\# $>$.

Reporters Without Borders. (2021a). Archives <https://rsf.org/en/ranking_list/archive $>$.

Reporters Without Borders. (2021b). Detailed methodology_<https://rsf.org/en/detailedmethodology $>$.

Ryan, C., Carragee, K. M., \& Schwerner, C. (1998). Media, movements, and the quest for social justice. Journal of Applied Communication Research, 26, 165-181.

Scoop. (2006). Sunday paper's grows, daily Herald maintains lead_<https://www.scoop.co.nz/ stories/BU0605/S00301.htm>. Scoop, May 12.

Silber, T. (2019). Dallas Morning News cuts 43 jobs, including 20 in newsroom, in "digital first" pivot<https://www.forbes.com/sites/tonysilber/2019/01/07/dallas-morning-news-cuts-43-jobsincluding-20-in-newsroom-in-digital-first-pivot/\#7ac7757e1569>. Forbes, January 7.

Sparks, C. (1993). Raymond Williams and the theory of democratic communication. In S. Splichal \& J. Wasko (Eds.), Communication and democracy (pp. 69-86). Ablex.

Spurr, D. (1993). The rhetoric of empire: Colonial discourse in journalism, travel writing and imperial administration. Duke University Press.

Stoney, G. (2005). [Personal conversation with Tony Dowmunt].

The Economist. (2018). Democracy index <https://www.eiu.com/topic/democracy-index>.

The Spinoff. (2018). 2018 in review <https://thespinoff.co.nz/2018-year-in-review/>. 
Tsfati, Y., \& Ariely, G. (2013). Individual and contextual correlates of trust in media across 44 countries <https://doi.org/10.1177/0093650213485972>. Communication Research, 41(6), 760782 .

UK Population. (2019). Population of Wolverhampton.

United States Census. (2019). Dallas city, Texas_<https://www.census.gov/quickfacts/ dallascitytexas $>$.

World Population Review. (2021). New Zealand population < http://worldpopulationreview.com/ countries/new-zealand-population/>.

\section{Notes}

1. Portions of this article have been reprinted from Kenix (2011).

\section{Related Articles}

De-Westernization and Decolonization in Media Studies

Communication and the Global South

Postcolonial Approaches to Communication and Culture

Pacific Media

Decolonization and Globalization in Communication Studies 